\title{
EXTENSIVE MOLECULAR LINE SURVEY FOR DARK CLOUDS
}

\author{
Norio Kaifu \\ Nobeyama Radio Observatory, National Astronomical Observatory \\ Nobeyama, Minamimaki, Nagano 384-13 Japan
}

\section{Nobeyama Spectral Line Survey}

Since 1984 the molecular line search for dark clouds, mainly TMC1, for wide frequency ranges in the short $\mathrm{cm}^{-}$and $\mathrm{mm}^{-w a v e r e n g t h}$ regions has been proceeded at Nobeyama Radio Observatory using the $45-\mathrm{m}$ telescope. The main collaborators are: H. Suzuki, M. Ohishi, S. Saito, Y. Yamamoto, K. Kawaguchi, and N. Ka ifu.

The unbiased and wide frequency coverage molecular line survey for dark clouds is by no means basically important from the standpoint of view of the interstellar chemistry and chemical evolution of dark clouds. However such extensive 1 ine survey has not been performed yet, because of some practical difficulties. Very narrow linewidth observed in dark clouds (about $0.5 \mathrm{~km} \mathrm{~s}^{-1}$ ) requires high frequency resolution, while the wide frequency region should be covered. The line intensity is relatively weak due to the low kinetic temperature of dark clouds. The narrow lines are very of ten difficult to distinguish from the confusion of weak spurious signals which are mixed from the local oscillators etc. Thus such survey is enevitably a very time consuming effort.
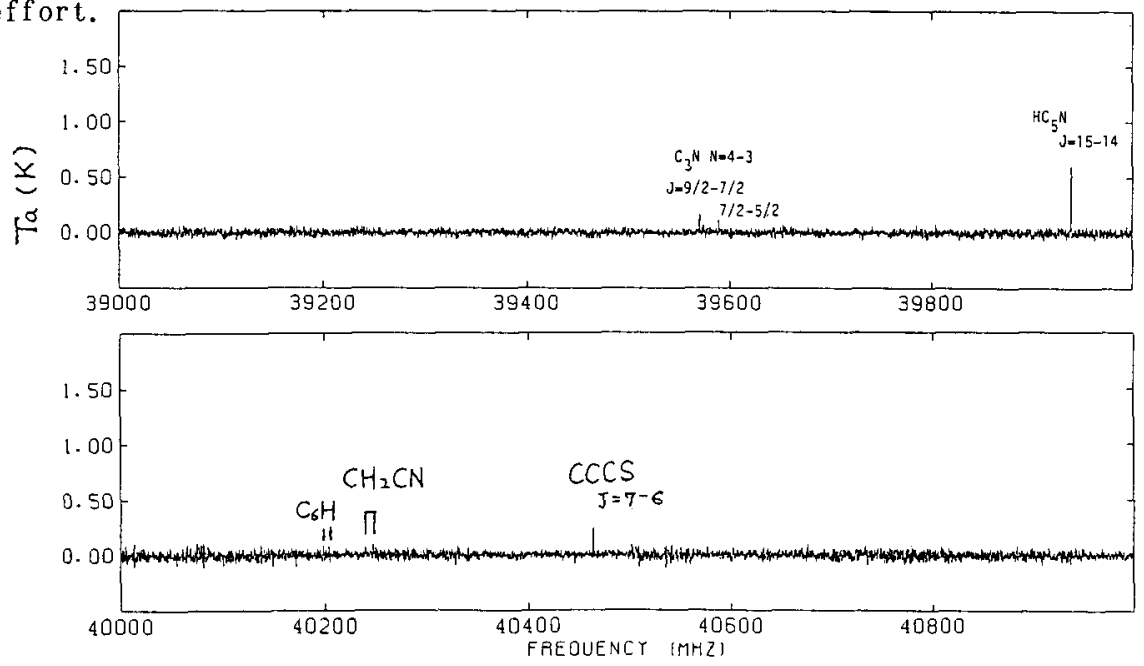

Figure 1. A sample of the $2 \mathrm{GHz}$ spectrum $(39-41 \mathrm{GHz})$ of $T M C 1$ taken with the $45 \mathrm{~m}$ telescope and the wideband $\mathrm{AOS}(250 \mathrm{KHz}$ resolution and 16000 channel). 
We have started the spectral line survey for TMC1 and some other sources by using the Nobeyama $45 \mathrm{~m}$ telescope, wideband receivers and A0S spectrometers.

The AOS, acousto-optical radiospectrometer, has been first developed extensively at the Tokyo Astronomical Observatory (Kaifu et al. 1977) and then at Nobeyama (kaifu and Chikada 1984). The Nobeyama A0S consists of two systems, one is the wideband A0S with 16000 channel outputs, $250 \mathrm{KHz}$ resolution and $8 \times 250 \mathrm{MHz}$ bandwidth. The other is the high-resolution system which provides 16000 channel, the resolution of $37 \mathrm{KHz}$ and the bandwidth of $8 \times 40 \mathrm{MHz}$. This large spectrometer system can be used simultaneously by connecting to one or two cooled receivers some of which also provide $2 \mathrm{GHz}$ simultaneous bandwidth. These large spectroscopic systems were essential for our survey, still the survey is by no means easy.

So far the survey has been performed in the frequency regions of $8.8-10.8 \mathrm{GHz}$, $14-16 \mathrm{GHz}, 18-21 \mathrm{GHz}, 22-24 \mathrm{GHz}, 36-50 \mathrm{GHz}$, and several fragmentary frequency bands in $88-110 \mathrm{GHz}$. The frontend receivers used were the cooled HEMT amps for the 8 $24 \mathrm{GHz}$ band, the cooled Schottky mixers and then a Nb SIS mixer later for the 36 $50 \mathrm{GHz}$ band, and a cooled Schottky mixer for the $88-110 \mathrm{GHz}$ region. The obtained rms noise temperature of the data vary from $3 \mathrm{mK}$ to $30 \mathrm{mK}$, depending on the receiver and observational conditions. A sample data is shown in figure 1.

The detailed results and discussion will be published elsewhere, and here we present the summary of the observed lines in table 1, and discuss some topics. As a whole we have detected 91 spectral Iines of 27 molecules (including two marginal detections) and 16 lines of 14 isotopic species in TMC1. Some 25 lines are not yet identified to any known molecules.

\begin{tabular}{|c|c|c|c|c|c|}
\hline \multirow[b]{2}{*}{ molecule } & \multicolumn{2}{|c|}{ number of 1 ines } & \multirow[b]{2}{*}{ molecule } & \multicolumn{2}{|c|}{ number of 1 ines } \\
\hline & $\begin{array}{c}\text { ma in } \\
\text { species }\end{array}$ & $\begin{array}{r}\text { isotopic } \\
\text { species }\end{array}$ & & $\begin{array}{c}\text { main } \\
\text { species }\end{array}$ & $\begin{array}{r}\text { isotopic } \\
\text { species }\end{array}$ \\
\hline $\mathrm{CO}$ & 1 & 2 & $\mathrm{C} \mathrm{H}_{3} \mathrm{C} \mathrm{N}$ & $1 ?$ & \\
\hline $\mathrm{NH}_{3}$ & 1 & & $\mathrm{C}_{2} \mathrm{H}_{3} \mathrm{C} \mathrm{N}$ & 2 & \\
\hline $\mathrm{C}_{3} \mathrm{~N}$ & 4 & & $\mathrm{H} \mathrm{N} \mathrm{C} \mathrm{O}$ & 1 & \\
\hline $\mathrm{C} \mathrm{S}$ & 2 & 2 & $\mathrm{CH}_{3} \mathrm{OH}$ & 1 & \\
\hline $\mathrm{CCS}$ & 4 & 1 & $\mathrm{CH}_{2} \mathrm{CN}^{*}$ & 11 & \\
\hline $\mathrm{CCC} \mathrm{S}$ - & 3 & & $\mathrm{H}_{2} \mathrm{C} \mathrm{S}$ & 2 & \\
\hline $\mathrm{C}_{4} \mathrm{H}$ & 10 & & $\mathrm{H}_{2} \mathrm{C} \mathrm{CO}$ & 2 & \\
\hline $\mathrm{C}_{6} \mathrm{H}^{*}$ & 12 & & $\mathrm{CH}_{3} \mathrm{COH}$ & $1 ?$ & \\
\hline $\mathrm{HCN}$ & 1 & 1 & $\mathrm{HC} \mathrm{O}^{+}$ & 1 & \\
\hline $\mathrm{H} C$ a N & 6 & 4 & $\mathrm{HC} \mathrm{S}^{+}$ & 1 & \\
\hline $\mathrm{HC}_{5} \mathrm{~N}$ & 9 & 6 & $\mathrm{HCCCOH}$ & 1 & \\
\hline $\mathrm{HC}, \mathrm{N}$ & 6 & & $\mathrm{C}_{3} \mathrm{H}_{2}$ & 2 & \\
\hline $\mathrm{HC}, \mathrm{N}$ & 2 & & $\mathrm{C}-\mathrm{C}_{3} \mathrm{H}$ & 4 & \\
\hline $\mathrm{CCCO}$ & 1 & & Unidentif ied & 25 & \\
\hline
\end{tabular}

Table 1. Observed molecular lines in the NRO spectral survey for TMCl - : Molecule newly detected or identified during this survey. 
During this survey we have detected several new interstellar molecules. These are: $\mathrm{C}_{6} \mathrm{H}$ (Suzuki et al.,1986), CCS (Suzuki et al.,1984, Kaifu et, al.,1987, Saito et a1., 1987), CCCS (Yamamoto et al., 1987a, Kaifu et al., 1987), cyclic $\mathrm{C}_{3} \mathrm{H}$ (Yamamoto et a l., 1987b), $\mathrm{CH}_{2} \mathrm{CN}$ (Irvine et al., 1988, Saito et al.. 1989), HCCCOH (Irvine et al., 1989). Especially the detection of CCS and CCCS added a new series of carbon chain molecules containing $S$, which is pretty abundant in TMC1 (see figure 2). The CCS was first detected as a strong unidentified line and 4 years later it was identified with a new molecule CCS by chance. The column density of CCS in TMC1 is $9 \times 10^{13} \mathrm{~cm}^{-2}$ and can be compared with those of $\operatorname{CS}\left(2 \times 10^{14} \mathrm{~cm}^{-2}\right)$ and of $\operatorname{HCN}\left(1.2 \times 10^{14} \mathrm{~cm}^{-2}\right)$.

\section{Carbon Chain Molecules and CCS}

The detections of CCS and CCCS provided a new aspect to the formation of carbon chain molecules, which characterize the dark cloud chemistry as can be seen in table 1. In spite of relatively low cosmic abundance of $S$ it seems that the sulphur-containing carbon chain molecules are pretty abundant. Also the series of $\mathrm{C}_{n} \mathrm{H}$ and $\mathrm{C}_{n} \mathrm{~S}$ chains show the continuous number of carbon atoms, though the relative abundances vary with $n$ (see figure 3 ). On the other hand the previously known carbon chains $\mathrm{HC}_{\mathrm{n}} \mathrm{N}$ are found for only odd $\mathrm{n}$.

Suzuki (1987) proposed an idea to explain such observational tendencies of carbon chain molecules. The carbon chain molecules may grow first as pure carbon chains which are "bones" of observed carbon chain molecules in the partially ionized $\mathrm{C}^{+}$regions of dark clouds (Suzuki 1983). Then the bones are combined with $H, N, 0$, S etc. to form stable molecules like $\mathrm{HC}_{n} \mathrm{~N}$. $\mathrm{C}_{n} \mathrm{~S}$ could be formed simultaneously to or just after the formation of carbon bones, because the low ionization potential of $S$ allow it to form the relatively deep $\mathrm{S}^{+}$region at the cloud surface, and here the sulphur chemistry should be active.

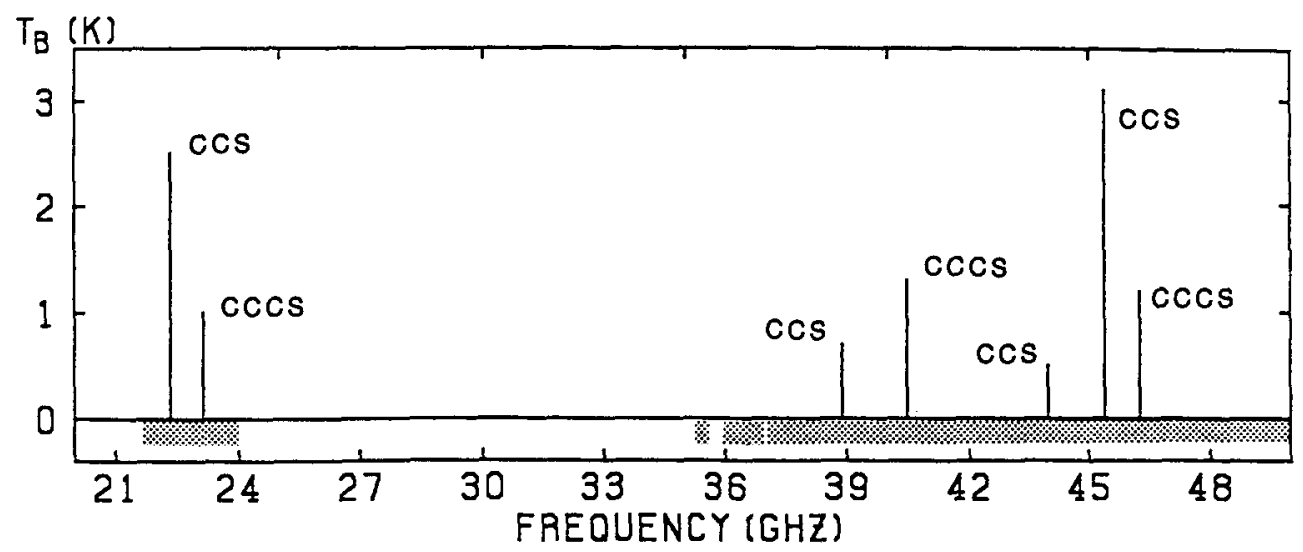

Figure 2. A schematic diagram of CCS and CCCS spectrum detected in the survey. The hatched area show the surveyed frequency range.

(taken from Kaifu et al., 1987) 


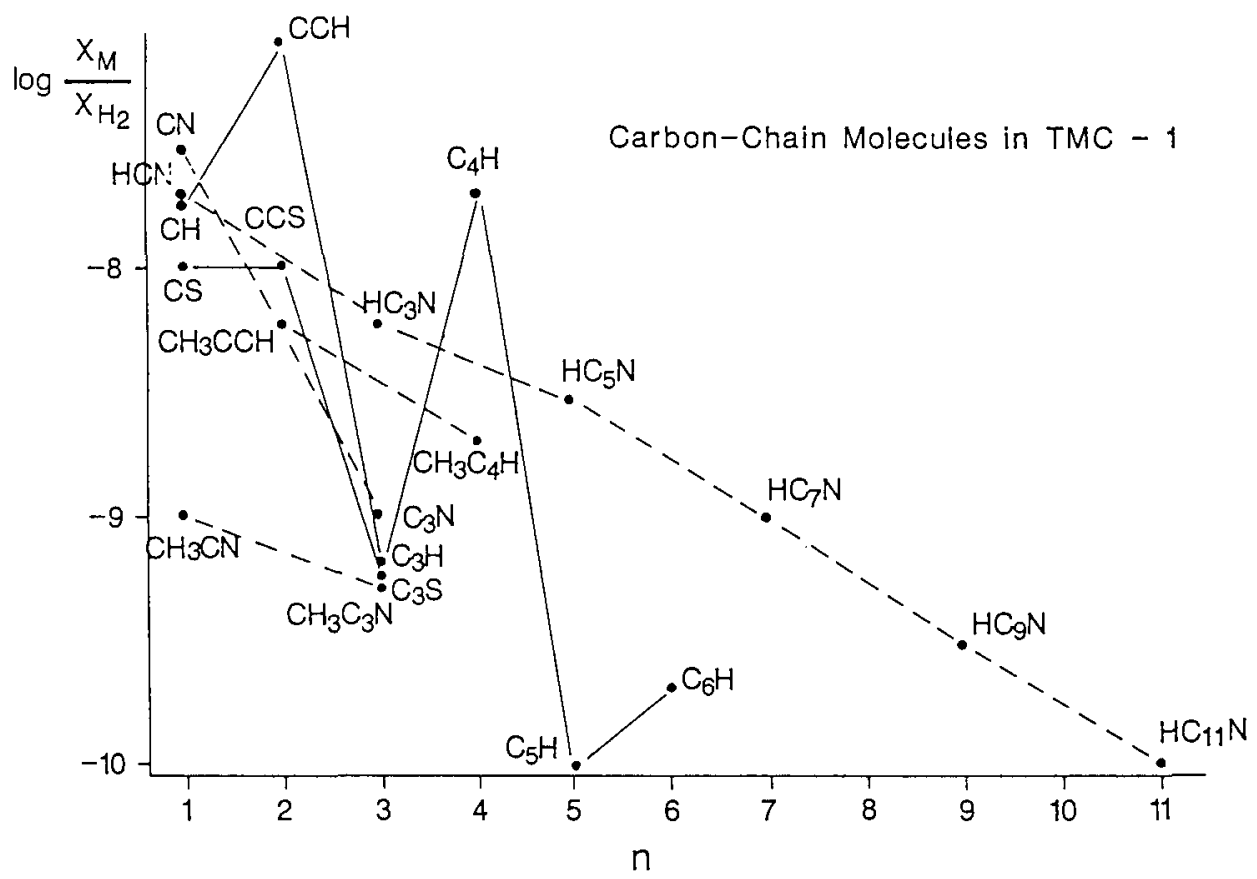

Figure 3. Abundances of carbon chain molecules in TMC1, as a function of number of carbon chain atoms $n$. Dashed line indicates the "odd $n$ only" and "even $n$ only" chain molecules. Values were taken from Irvine et al. 1987, Suzuki et al. 1986, Saito et al. 1987, Yamamoto et al. 1987a.

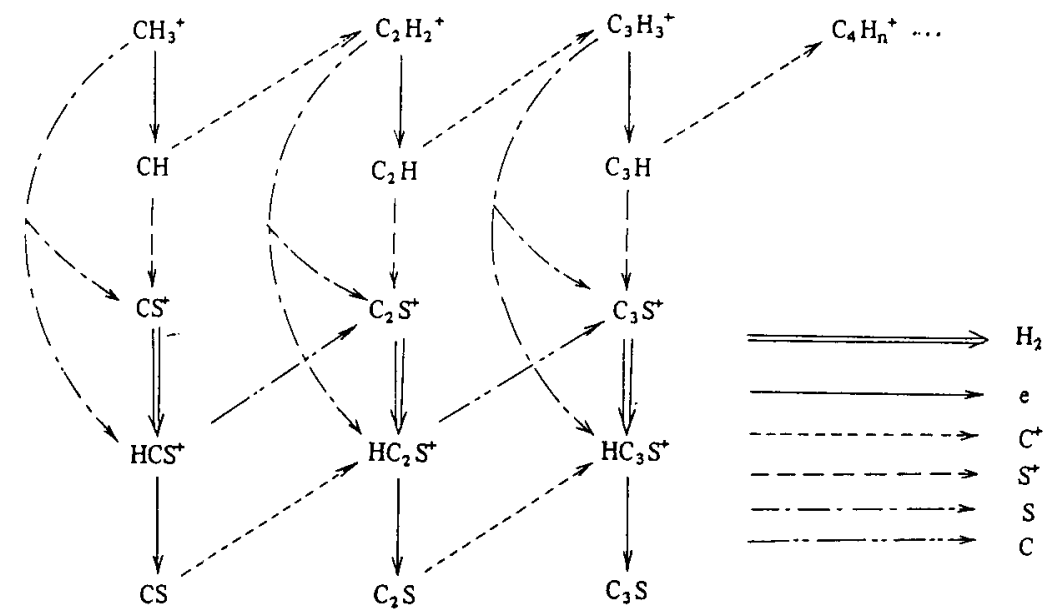

Figure 4. A schematic flow of possible $C_{n} S$ formation process in the partially ionized region, taken from Suzuki (1987). 
A schematic diagram of $\mathrm{C}_{\mathrm{n}} \mathrm{S}$ formation in the $\mathrm{S}^{+}$region is given by Suzuki (figure 4). The $\mathrm{C}_{n} \mathrm{~S}$ chains are not very stable and will be changed to be more stable species in denser region. Therefore the $C_{n} S$ might be a good probe of the cloud evolution to trace the chemistry in the various stages of contraction of dark clouds.

We are making extensive observations to test the distribution of CCS in various dark clouds and inside some selected clouds and to compare them to those of other molecules like CS, $\mathrm{NH}_{3}, \mathrm{HC}_{3} \mathrm{~N}$ etc(Yamamoto et al., 1989, Hirahara et al., 1989). Figure 5 shows a comparison of distributions of CCS and CS in TMC1, showing remarkable difference between the distributions of these two molecules. Another remarkable fact about $\operatorname{CCS}$ is that it cannot be found in the star forming regions where the density is high and accompanied with various shocks and heating effects. Such observational facts would be interpreted in terms of the combination of the chemical and physical evolution of the dark clouds.

Furthermore the recent detection of $\mathrm{CH}_{2} \mathrm{CN}$ (Irvine et al.,1988, Saito et al., 1989) dramatically showed that abundant (NL of $10^{13}-10^{14} \mathrm{~cm}^{-2}$ ) complex organic molecules might be detected as very weak signals because of their complex energy level structures. Such spectral lines would distribute in relatively longer wavelength regions. In NRO we pian to extend our survey to complete the frequency range from $8 \mathrm{GHz}$ to $50 \mathrm{GHz}$ with higher sensitivity, by using wideband cooled HEMT amplifiers and SIS receivers. Also the spectral scans for $70-120 \mathrm{GHz}$ by using new SIS receivers will start in next winter.
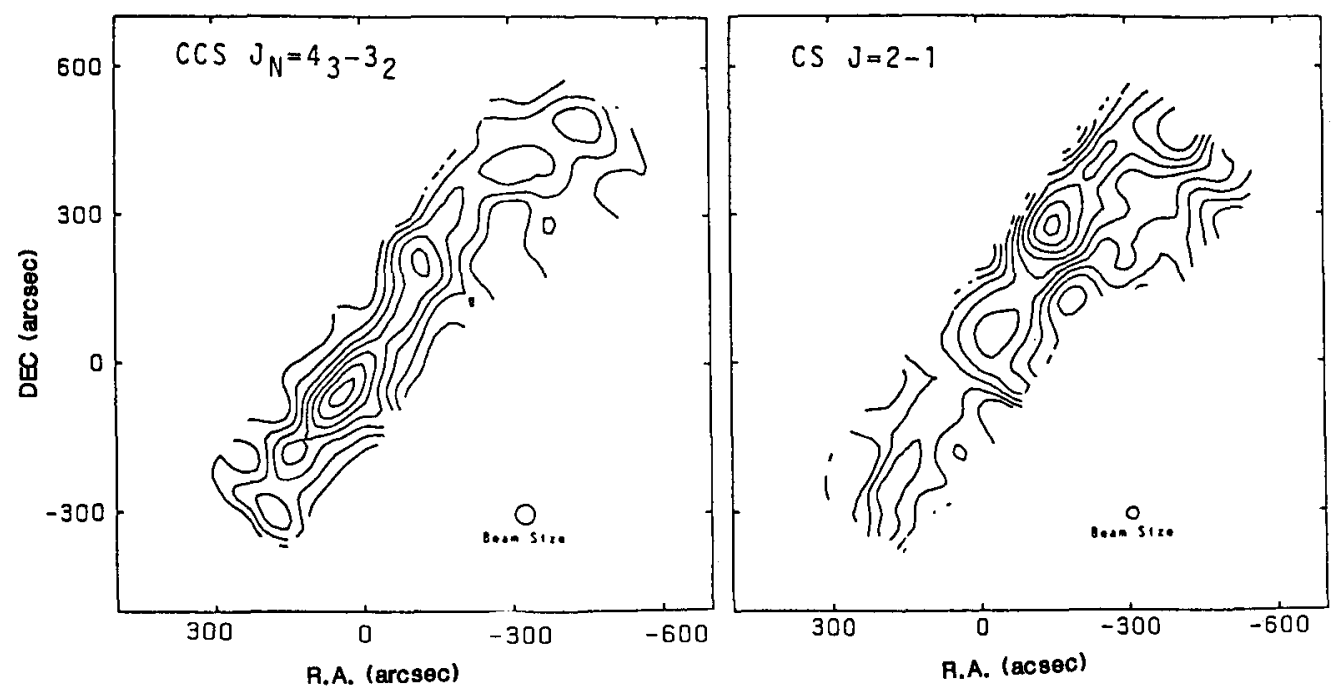

Figure 5. A map of CCS distribution in TMC1 (left) compared with an $\mathrm{NH}_{3}$ map (right), taken with the $45 \mathrm{~m}$ telescope (Hirahara et al., 1989). 
The author offer his condolences to the late Dr. Hiroko Suzuki (1947-1987), who was a very distinguished astrophysicist, the nost active staff member of Nobeyama Radio Observatory and was our best colleague and friend.

She was one of the pioneers of astrochemistry, she was at the center of the Nobeyama molecular line survey. She died on 22 November, 1987, the result of a car accident. Her great contributions to astrochemistry and to radio astronomy, and her very active life will remain in our memory forever.

\section{REFERENCES}

W. M. Irvine, F.P.Schloerb, A.Hjalmarson, and E. Herbst, in: Protostars and Planets II, (D. C. Black and M.S. Matthews, ed.), pp.579, Univ.Arizona Press, (1985).

W. M. Irvine, P. Friberg, A. Hjalmarson, S. Ishikawa, N. Ka ifu, K. Kawaguchi,

S.C.Madden, H. k. Mat thews, M. Ohishi, S. Saito, H. Suzuki, P. Thaddeus,

B. E. Turner, S. Yamamoto, and L.M.Ziurys, Astrophys J. (Letters), 334, L107, (1988).

W. M. Irvine et al., submitted to Astrophys. J., (1989)

N. Kaifu, N. Ukita, Y. Chikada and T.Miyaji, Publ.Astron.Soc.Japan, 29, 429, (1977)

N. Kaifu, and Y. Chikada, in: URSI Symposium on Millimeter and Submillimeter

Astronomy, (NRO Report $\underline{63}$ ), (1984).

N.Kaifu, H. Suzuki, M. Ohishi, T.Miyaji, S. Ishikawa, T. Kasuga, M. Morimoto, and S. Saito, Astrophys. J. (Letters), 317, L111, (1987).

Y.Hirahara, Thesis, Faculty of Science, University of Tokyo, (1989).

S. Saito, K. Kawaguchi, S. Yamamoto, M. Ohishi, H. Suzuhi, and N. Kaifu,

Astrophys. J. (Letters), 317, L115, (1987).

S. Saito, S. Yamamoto, W. M. Irvine, L. M.Ziurys, H. Suzuki, M.Ohishi, and N. Kaifu,

Astrophys. J. (Letters), 334, L113, (1988).

H. Suzuki, Astrophys.J., 272, 579, (1983).

H. Suzuki, N.Kaifu, T.Miyaji, M. Morimoto, and M. Ohishi,

Astrophys. J., 282, 197, (1984).

H. Suzuki, M. Ohishi, N.Kaifu, S. Ishikawa, T.Kasuga, K. Kawaguchi, and S. Saito,

Publ.Astron. Soc. Japan, 38, 911, (1986).

H. Suzuki, S. Yamamoto, S. Sa ito, M. Ohishi, N. Kaifu, S. Ishikawa, and A. Murakami,

a report in: IAU 3rd Asian Pacific Regional Meeting, Peking, (1987).

S. Yamamoto, S. Saito, K. Kawaguchi, N. Kaifu, H. Suzuki, and M.Ohishi,

Astrophys.J. (Letters), 317, L119, (1987a).

S. Yamamoto, S. Saito, M. Oh ishi, H. Suzuki, S. Ishikawa, N. Kaifu, and A. Murakami, Astrophys. J. (Letters), 322, L55, (1987b).

S. Yamamoto et al., (1989), in preparation. 